\title{
Launching an information and digital literacy badge and certificate pro- gram in collaboration with a teaching and learning center
}

n fall 2019, the University of Wyoming

(UW) Libraries launched an information and digital literacy badge and certificate program in partnership with the Ellbogen Center for Teaching and Learning (ECTL), housed in the UW Libraries main branch. ECTL crafts programing and provides support for graduate students, staff, and faculty who teach on our campus by employing instructional designers.

The Information and Digital Badge and Certificate Program was created when ECTL redesigned their Teaching and Learning Certificate, and it features many services and resources that UW Libraries already offers (i.e., information literacy instruction and research consultations). This article will detail the redesign of the certificate program, how the current teaching and learning certificate was designed, and conclude with lessons learned from the first year of the program as well as future goals.

\section{A total program redesign}

The original Teaching and Learning Certificate was run solely by ECTL and focused heavily on the scholarship of teaching and learning, teaching philosophies, and teaching observations. The original program was open-ended, self-directed, and did not provide much structure or support for faculty, graduate students, or staff to complete the program. Consequently, this made it difficult for program participants to complete the certificate in a timely manner. While there were nearly 300 people enrolled in the program, only a small number of people graduated each year (approximately ten people).
Additionally, ECTL also ran a smaller diversity, equity, and inclusion certificate that was run by a different instructional designer and featured different protocols, while having many duplicate enrollees.

In the spring semester of 2019 , the instructional design librarian and student success librarian initiated a conversation with UW Libraries administration about providing teaching and research support by potentially integrating library services into the two ECTL certificates. The library administration was supportive of this plan as it aligned with the university-wide initiative at UW to create more badging programs.

The librarians approached ECTL with the simple proposal of advertising library workshops to certificate participants. This would allow participants to gain points towards the certificate by bringing their class into the library. ECTL wanted to redesign the certificate program, and, subsequently, asked for librarian help and support. At a second meeting, an ECTL instructional designer and the librarians used whiteboards to sketch out a template of

\footnotetext{
Samantha Peter is instructional design librarian at the University ofWyoming Libraries, email:scook13@uwyo. edu, Kristina Clement is student success librarian at the University of Wyoming, email: kclemen8@uwyo. edu, Shannon Sheridan is data management librarian at the University of Wyoming, email: ssherid3@uwyo. edu, and Hilary Baribeau, formerly of the University of Wyoming, is now scholarly communications librarian at Colby College, hbaribea@colby.edu
}

(C) 2021 Samantha Peter, Kristina Clement, Shannon Sheridan, and Hilary Baribeau 


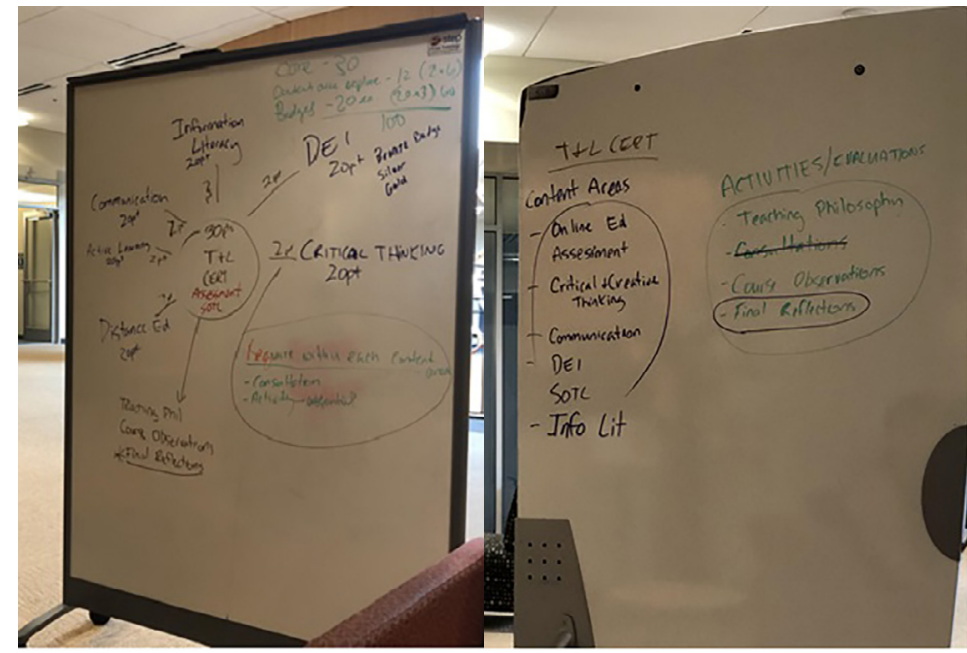

Photograph of the whiteboards used to sketch out the new Teaching and Learning Certificate and Badge Program.

what would become the new Teaching and Learning Certificate and Badge Program.

\section{The Information and Digital Literacy Badge Program}

In its new form, the ECTL certificate pro- to earn badges in the focus areas without having to complete the full certificate. As part of the entire certificate, participants are required to watch a video about the information and digital literacy certificate and take a library pretest. Points are earned by writing short reflections (about one paragraph) in the online certificate portal on activities undertaken, with one point equal to one hour of activity. For example, a participant who attended a one-hour workshop would write a reflection on the experience and justify the significance and applicability of their experience to their badge subject area. ${ }^{1}$ gram remains a self-directed program where participants complete a program core and choose their preferred focus areas en route to earning badges and/or a full certification. There are currently seven focus areas, of which information and digital literacy is one. Completion of the full cer-

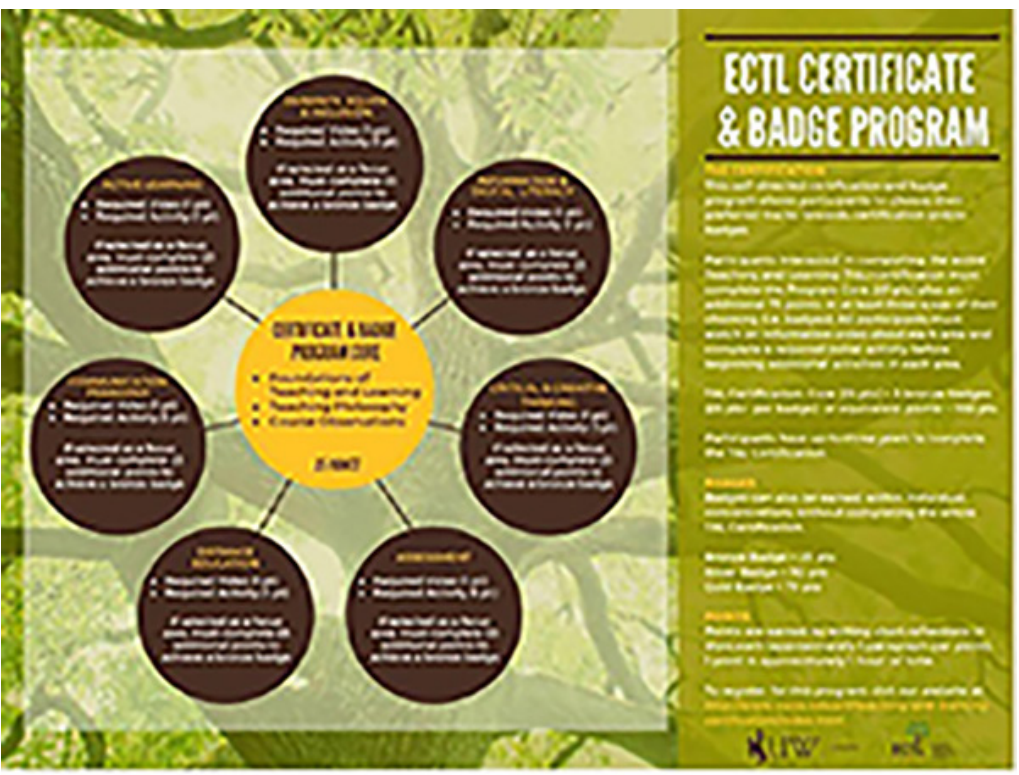

tificate requires Graphic advertisement promoting the newly redesigned Teaching and Learning earning 100 Certificate.

points: 25 points come from the program core and 75 points come from a combination of focus areas. Participants also have the option
The Information and Digital Literacy Badge focuses on encouraging faculty, staff, and graduate students to intentionally incorporate 
information and digital literacy into their work. In order to give participants an idea of the kinds of activities they could complete to earn points, the librarians designed a menu of items that features existing services that the UW Libraries offer.

Examples of menu items include working with a librarian to design LibGuides or tutorials for a course, applying for an Open Educational Resources (OER) alt-text book grant, attending a library workshop, teaching a session with library resources or the collections at the American Heritage Center (the archival institution housed on our campus), creating data management plans, and much more. This menu incorporates all of the different services or spaces within the UW Libraries, including the American Heritage Center, UW Libraries Special Collections, and the Makerspace housed within the libraries.

Having participants complete activities within the program requires no extra work for librarians. Essentially, this is another way for the library to creatively advertise its services with the added value of participants earning program points.

Four librarians contributed to the creation and content of the badge program: the instructional design librarian, the student success librarian, the digital scholarship librarian, and the data management librarian. Currently, all but the digital scholarship librarian manage the program. The instructional design librarian is the team lead, managing much of our online presence and acting as our main contact with ECTL. The student success librarian is co-lead, assisting the instructional design librarian when needed. The data management librarian provides subject-specific expertise and services to program participants.

One of the main goals of this certificate is to involve the entire library in the different programming. We are currently working to include our Resource, Discovery, and Management Division, which houses our collection development, e-resources, cataloging, and technical services. The American Heritage Center is also an official partner in this badge program and has included the majority of the services they provide, including instruction, grants, digital content, and records management as menu options for participants to earn points.

Another unique element to the badge program is the creation of fast-tracks. Because there are many options for participants to earn points, we wanted to create easy ways for participants to earn the 25 -point bronze badge. This creates a more structured way for participants to earn badges quickly. Each fast-track is centered around specific themes or skills. The first fast-track is centered around the UW Libraries OER initiative managed by the digital scholarship librarian. Participants can earn a badge by applying for and completing an OER grant and presenting on their OER implementation. Librarians are looking to incorporate more fast-tracks, potentially focusing on instruction, research data, and archives, as we continue to develop the badge program.

\section{The first year}

The first year of the Information and Digital Literacy Badge has been a period of rapid change and growth with positive feedback overall from both participants and organizers. There are currently 53 participants in the redesigned Teaching and Learning Certificate Program and 20 participants within the Information and Digital Literacy Badge. Currently, enrollment in the Information and Digital Literacy Badge represents 38\% of total enrollment across the entire certificate and badge program. Half of the Information and Digital Literacy Badge participants are active (i.e., have submitted prequestions or reflections for activities).

So far, none of the participants have completed the program. However, the lead librarians have conducted consultations with $41 \%$ of badge participants, indicating high engagement between librarians and participants.

The program has had several successes over this first year. One such example was presenting twice at the Lunch and Learn series sponsored by ECTL. Once a week, presenters from around campus discuss different topics geared toward improving teaching and learn- 
ing. Librarians cotaught two lunch sessions: "Data Management and Data Literacy in Research Assignment Design” and "Designing a Research Assignment with Information and Digital Literacies."

We promoted our badge program during both of the sessions and as a result saw increased enrollment and participation. Another opportunity for collaboration is at the ECTL $S \mathrm{u} \mathrm{m}$ mer Boot C a m p. This series consists of monthly half-day workshops instructors can a t te nd.

\begin{tabular}{|l|l|l|}
\hline & Unacceptable & Acceptable \\
\hline $\begin{array}{l}\text { Description of activity, } \\
\text { including date completed }\end{array}$ & $\begin{array}{l}\text { Activity is not properly } \\
\text { described. }\end{array}$ & Activity is properly described. \\
\hline $\begin{array}{l}\text { Relation to } \\
\text { information/digital literacy }\end{array}$ & $\begin{array}{l}\text { Participant does not properly } \\
\text { relate the activity to } \\
\text { information and/or digital } \\
\text { literacy. }\end{array}$ & $\begin{array}{l}\text { Participant properly relates } \\
\text { the activity to information } \\
\text { and/or digital literacy }\end{array}$ \\
\hline Learning/major takeaways & $\begin{array}{l}\text { Participant does not describe } \\
\text { any learning or major } \\
\text { takeaways from the activity. }\end{array}$ & $\begin{array}{l}\text { Participant describes at least } \\
\text { one learning or takeaway } \\
\text { from the activity. }\end{array}$ \\
\hline $\begin{array}{l}\text { Relation to your work } \\
\text { (teaching or research) }\end{array}$ & $\begin{array}{l}\text { Participant does not properly } \\
\text { relate the activity to their own } \\
\text { teaching and/or research. }\end{array}$ & $\begin{array}{l}\text { Participant properly relates } \\
\text { the activity to their own } \\
\text { teaching and/or research. }\end{array}$ \\
\hline $\begin{array}{l}\text { Justification for point(s) } \\
\text { earned }\end{array}$ & $\begin{array}{l}\text { Participant does not justify } \\
\text { the number of points they } \\
\text { should earn for the activity. }\end{array}$ & $\begin{array}{l}\text { Participant justifies the } \\
\text { number of points they should } \\
\text { earn for the activity. }\end{array}$ \\
\hline
\end{tabular}

Each Boot Camp is their reflections. organized around a theme with presenters from across campus (including the Libraries). Another accomplishment from this first year is the positive feedback we have received on our menu of options for participants. Several participants have commented on how helpful the menu is because it provides guidance on a variety of activities and opportunities that count towards earning the badge and approximately how many hours one can earn from that particular activity.

One aspect of the program we have found challenging is managing the self-directed nature of the certificate program. This approach allows participants to structure their activities within their own schedules. However, there is no structured timeline for completion of the certificate and badges, other than a three-year time limit, so it is difficult to maintain consistent contact with badge participants and encourage them to keep up their momentum. Consequently, we have begun to contact participants and work to develop a plan for points to finish the program. We hope to continue facilitating these conversations as the badge program grows.

As we continue to develop the Information and Digital Literacy Badge, we are considering different ways to incorporate the feedback we have received from the first year. We hope to continue to add to our menu of options by in-

corporating more $1 \mathrm{i} b \mathrm{rary}$ services and offering more fast-track options. $\mathrm{Th}$ e r e are also potential partnerships outside of the Libraries, which include the Art $\mathrm{Mu}$ seum, the Geology Museum, and the College of Engineering Makerspace.

We have also encountered problems with consistency between the reflections of various badge focus areas and the certificate core. The activity reflections often need some adjustments after the participant's initial submission in order for the participant to earn their points. For example, we have had participants only say they attended a workshop rather than properly reflect on how the workshop relates to information and digital literacy and applies to their teaching and/or research. To create a higher and more consistent standard of work, we have developed an assessment rubric and sample reflections that are available to participants to help increase the awareness of expectations for this badge program.

Another challenge is getting the entire program management team on board with creating certain standardized elements for the Teaching and Learning Certificate. For example, our Information and Digital Literacy Badge 
Program has implemented a pre- and post-test for all program participants to assess their growth and progress as they complete their badge. All participants answer five reflective questions about information and digital literacy when they start the badge program, and later answer the same five questions when they are ready to finish. Using the same questions for the pre- and post-test allows us to compare and assess what they have learned. We had hoped to create a standardized pre- and post-test across all of the different badges but have yet to get buy-in across the board.

\section{COVID-19}

COVID-19 and the moving online of all services and courses in Spring 2020 through Spring 2021 has had a major impact on the number of active participants in the Teaching and Learning Certificate. As with many other campuses across the world the University of Wyoming went to fully online services in March 2020 and the libraries shut their doors. This stopped many of the different workshops, instruction sessions, and programs that UW Libraries and the ECTL had planned. Additionally, graduate students, faculty and staff all had higher priorities with moving their classes online. This meant we saw a large drop in participation after March 2020.

We had two graduate students who were on track to graduate from the Teaching and Learning Certificate in April 2020 with badges in Information and Digital Literacy who have not completed their activities and have now graduated from the University of Wyoming.

Summer 2020 to Spring 2021 brought renewed participation in the program. We jumped from $33 \%$ of the participants being active (i.e. participating in the pre-tests or submitting reflections) in the Information and Digital Literacy Certificate to $50 \%$ of the participants being active.

The Instructional Design Librarian worked with ECTL to provide content for both week- and month-long courses in which a majority of faculty on the UW campus participated. Participants in the final day or week of the course worked with topics on open education, data management, information and digital literacies, and the support the libraries can provide in those areas. Videos and written content were created for these topics. This is where the focus has continued to be while faculty continue to adapt to the changing environment the COVID pandemic has brought. Participants can receive points within the Teaching and Learning Certificate for participating in these week- or month-long workshops.

\section{Future goals}

We continue looking towards the future of the Information and Digital Literacy Badge and how we can expand our program offerings. We are actively pursuing more fast-tracks akin to the one already in existence for OER. The data management librarian is currently creating a data management fast-track, which will consist of following research data through its life cycle, with activities including consulting with a librarian, creating a data management plan, and storing data in a data repository.

Another fast-track in the works is for instruction, where an instructor can come and consult on assignment or syllabus design, work with a librarian to implement changes in their class, or incorporate new library services, such as special collection or course reserves.

As this program continues to grow, we hope to increase the number of participants involved, expand the recommended activities for participants, further the awareness of our program through direct marketing, and welcome new academic partners to the program. We want to continually evaluate what parts of the program are successful and what areas can be improved to help participants finish the program to receive their badges.

We also hope to have participants progress beyond the basic 25-point bronze badge and earn silver (50 points) and gold badges (75 points), eventually completing a full 100-point certificate in information and digital literacy. The Information and Digital Literacy Badge has been a valuable collaborative experience and a model for other library collaborations across campus.

\section{Note}

1. A Menu of Activities for the Information and Digital Literacy Badge Program, along with pre- and post-test questions, are available in the University of Wyoming institutional repository. $\boldsymbol{n}$ 